\title{
Exploration of the Path to Improve the Innovative Quality and Ability of College and University Students
}

\author{
Daheng Shang* \\ Discipline Inspection Commission, Henan University of Science and Technology, Luoyang 471000, Henan Province, China \\ *Corresponding author: Daheng Shang, jyhnnl@126.com \\ Copyright: ( $) 2022$ Author(s). This is an open-access article distributed under the terms of the Creative Commons Attribution License (CC \\ BY 4.0), permitting distribution and reproduction in any medium, provided the original work is cited.

\begin{abstract}
The improvement of college and university students' innovative quality and ability is necessary for colleges and universities to carry out the fundamental task of establishing moral education and cultivating innovative talents for the Party and the country. At present, there are several problems in the innovation of college and university students, including imperfect system and mechanism, incomplete integration of resources, insufficient understanding of themselves, and so on. In view of these problems, this study actively explores the path to enhance the innovative quality and ability of college and university students by improving the system and mechanism at the macro level, integrating resources to form synergy at the meso level, and motivating college and university students to engage in the process of ascending at the micro level.
\end{abstract}

Keywords: College students; Innovation; Quality and ability enhancement; Path

Online publication: February 18, 2022

\section{Introduction}

With the development of globalization, the competition among countries is increasingly intense. And innovation, especially the cultivation of college and university students with innovative quality and ability, is the "magic weapon" to ensure victory. Based on the actual situation of colleges and universities, this study explores the path to improve the innovative quality and ability of college and university students by means of improving the mechanism at the macro level, integrating resources at the meso level, and motivating college and university students at the micro level.

\section{Current situation of the innovative quality and ability of college and university students}

\subsection{Mechanism}

Colleges and universities have been paying great attention to innovation. There are several functional departments that have undertaken the task as pilots. However, they have not passed a sound working mechanism that unifies management and organization at the university level neither have they established a systematic system to ensure daily implementation. In addition, they have not constructed a duplex communication mode inside and outside the classroom or established an innovation cultural environment in campus from the perspective of mechanism. 


\subsection{Resource}

The cultivation of innovation among college and university students is mainly carried out in the form of special lectures and extracurricular activities. There is a serious lack of innovation and entrepreneurship elements in the construction of the talent system. The talent cultivation system of colleges and universities is out of line with the concept of innovative education, and there is no integration of the relationship between teachers and students, between graduate students and undergraduates, as well as between on-campus and off-campus from the perspective of innovation to form a synergy.

\subsection{Self-awareness}

In addition to the current restrictions by colleges and universities on students' innovation, college and university students face the real society directly through new media. With the impact of various temptations, multiple value concepts, and the hardship of the innovation process itself, these students lack interest in innovation and are reluctant to try or explore.

\section{The path to improve the innovative quality and ability of college and university students}

In view of the problems of improving the innovative quality and ability of college and university students, it is necessary to consider the actual situation of colleges and universities. Colleges and universities should not only provide guarantee for innovation mechanism at the macro level, but also integrate various resources to create conditions and guide college and university students to put into practice what they have learned, in order to realize the virtuous cycle of combining learning with application, applying learning to application, and using what they have learned effectively.

\subsection{Improving the mechanism from the macro level}

\subsubsection{Constructing a perfect system}

The improvement of innovative quality and ability of college and university students is a systematic and fundamental process, which requires ensuring its scientific advancement from the institutional level ${ }^{[1]}$. At the school level, it is necessary to construct the system for unified leadership and organization. Each functional department and grassroots school should build the working mechanism of coordination and linkage for the specific implementation. Moreover, it is necessary to establish a system involving the personal interests of teachers, such as title evaluation, to inspire them to participate in it. At the same time, it is also suggested to have a supporting system for the development of student Party members, cadre selection, promotion and merit evaluation, etc. By means of perfecting the system, the improvement of students' innovative quality and ability would be put into practice.

\subsubsection{Establishing a duplex communication mode inside and outside the classroom}

In order to achieve the improvement of college and university students' innovative quality and ability, it is important to realize the organic integration of the main position in the classroom and the main channel outside the classroom. Classroom teaching is the basic theoretical source of innovation for students. College and university students are able to master basic scientific methods and theoretical contents of the field as well as understand the latest innovation frontier of the discipline through the classroom. Besides, the basic theoretical contents learned in the classroom should be combined with the actual practice and applied in laboratories, innovation centers, and the real society. Only through the practical process of solving real problems can students deeply understand the connotation of these theories and master the path as well as method of transforming theory into reality. 


\subsubsection{Creating an innovative cultural environment in campus}

Colleges and universities should explore the organic integration and effective practice of innovation as well as campus culture construction, with innovation as the important factor of campus culture. In the construction of an innovative campus culture, it is suggested to condense the spirit, stimulate innovation, play the guiding role of campus culture, change the concept, put students first, respect students' subjective initiative and personality development, respect the law, stimulate interest, guide students to develop independent thinking and active learning, focus on practice, support innovation, as well as encourage students to be innovative and brave. At the same time, it is important to enhance the innovative environment in campus, reflect the innovative spirit of college and university students, as well as mobilize the enthusiasm of teachers and students for innovation. In addition, colleges and universities should give full play to the dual driving role of online and offline, focus on innovation in campuses, tap into innovative factors, integrate innovation into the cultural environment in campus, and create a strong innovative cultural environment through the organic integration of the first classroom and the second classroom along with modern communication media.

\subsection{Integrating resources at the meso level to form a synergy}

\subsubsection{Relationship between teachers and students}

In the process of improving the innovative quality and ability of college and university students, there is a need for both the foundation and project topics of on-campus advisors of professional disciplines as well as off-campus real-life entrepreneurs (off-campus advisors), who are concerned with the frontier orientation of the country and the real social needs. On-campus advisors focus on the cultivation and guidance of basic innovation and entrepreneurship knowledge as well as guide students through topics, lectures, tutorials, and exchanges on relevant topics and theories. Off-campus advisors are those who have experienced the process of innovation and entrepreneurship in the real world, as well as have undertaken successful innovative and entrepreneurship cases. They are able to transform ideas and relevant competitive project topics into realistic entrepreneurial products with their strong practical experience and operational skills.

\subsubsection{Relationship between graduate and undergraduate students}

In the process of improving the innovative quality and ability of college and university students, it is necessary to realize the seamless connection between graduate students and undergraduates, where graduate students lead undergraduates to grasp the research trends in the same field, determine the core competitiveness of existing projects, and achieve innovative breakthroughs. In the process of carrying out projects, graduate students lead undergraduates to carry out innovation and entrepreneurship with professional academic advantages as well as innovative and entrepreneurship experience, so as to avoid the low level and singularity of undergraduates' innovation and entrepreneurship. Graduate students need to guide undergraduate students to carry out projects in aspects and matters that require attention, so as to help undergraduates cultivate their awareness of independent innovation and entrepreneurship as well as the necessary skills in software operation.

\subsubsection{Relationship between on-campus and off-campus}

In the process of improving college students' innovative quality and ability, colleges and universities should truly implement innovation and provide their students with opportunities as well as platforms for innovation and entrepreneurship. This includes the Scientific and Technological Innovation Association, MBI (Master of Business Innovation) Scientific and Technological Innovation Club, and other student associations, so that those students with similar interests can gather together for ideological collision and action cooperation, 
thus stimulating their desires and passion for innovation and entrepreneurship. Subsequently, more innovative and entrepreneurship plans can be proposed through the interaction among students with different subject backgrounds. With the guidance of teachers, the ideas of students will be more effective

${ }^{[2]}$. Outside the campus, colleges and universities can establish innovative and entrepreneurship incubation bases as well as industry-university-research cooperation bases for their students. In that way, enterprises can also be incubated at these places, and alumni resources can also be widely shared.

\subsection{Motivating college and university students to engage in the process of ascending at the micro level}

\subsubsection{Basic cognitive stage}

This stage is dominated by "necessity." In the innovation and entrepreneurship curriculum, each student is required to participate in primary innovative events organized by the college or university, visit the physical objects of the practice platform and projects, as well as learn the necessary software for enhancing one's innovative ability, such as SolidWorks and MCU programming. At the same time, colleges and universities should offer hardware and software courses as well as encourage advisors and innovative backbone students to train and guide other students. In addition, college and university students should be encouraged to participate in the design of the workshop, the actual production process in the experimental room, and the defense roadshow in the school competition, to experience the ambience of innovation competition personally.

\subsubsection{Participation stage}

This stage is dominated by skills. In the curriculum, students should participate in the necessary competitions at the school level. They should also be encouraged to participate in competitions of other disciplines based on their interests. Under the guidance of advisors and the person-in-charge of the innovative project, college and university students should be encouraged to participate in the operation of machine tools and the conception of project creativity, use processing tools, write project plans, attend roadshows, etc. At the same time, they should understand the cutting-edge trend of advisors and deeply participate in the research of relevant cutting-edge projects with the approval of advisors. Besides, they can be given the opportunity to lead their teams to participate in high-level events and carry out project designs, productions, tests, improvements, and roadshows. This would be a chance for them to compete with other colleges and universities in the province or even the country as they lead all processes and links of the roadshow, as well as the defense and dynamic process of the activities at the competition site.

\subsubsection{Roadshow operation stage}

This stage is dominated by organization and management. With their strong interest, they will gain strong professional skills through the project process along with organization and management skills through the team guidance process. As the backbone and person-in-charge of the project, it is imperative to pay attention to cutting-edge innovative technologies, grasp the research trends in the same field, focus on the "pain spots" of the market involved in the project itself, closely integrate professional knowledge with the internal logic of the project, determine their own existing project explosion points and core competition points, and then achieve innovative breakthroughs. In addition, it is important to divide the work among team members, deeply understand the advisors' scientific research topics and project experiments, become a member of the advisors' team, guide the team members to carry out conception, design, production, test, improvement, perfection, roadshow, and the actual combat of the project, as well as recruit students from other colleges and universities required by the project to complement each other's strengths. At the same time, it is 
necessary to write relevant patents and publish relevant papers, so that the project can reach a certain standard in China ${ }^{[3]}$. In national competitions, colleges and universities should improve students' ability at a higher level, lead students to compete with domestic first-class universities on the same stage, cultivate students' strengths, and improve their innovative quality and ability.

\section{Conclusion}

Improving the innovative quality and ability of college and university students is a systematic and basic project, which is not only about the practice of strengthening moral education and cultivating people, but also the cultivation of innovative talents for the Party and the state. Therefore, it is necessary to improve the system and mechanism from a macro level; it is also imperative to integrate resources from the meso level to form a synergy; last but not least, college and university students should be encouraged to engage in the process of ascending at the micro level, so as to achieve the expected effect.

\section{Disclosure statement}

The author declares that there is no conflict of interest.

\section{References}

[1] Marx K, Engels F, Lenin V, et al., 1998, The Complete Works of Marx and Engels [Works Compilation $\&$ Translation Bureau of the Central Committee of the Communist Party of China], People's Publishing House, 99.

[2] Lin S, 2021, Innovation and Entrepreneurship Education and Entrepreneurial Practice in Colleges and Universities: Study on the Integration and Development of Innovation and Entrepreneurship Education for College Students in the Era of Dual Innovation. Journal of the Chinese Society of Education, 2021(09): 117.

[3] Yang G, 2016, Extracurricular Training of College Students, China Social Science Press, 162.

Publisher's note

Bio-Byword Scientific Publishing remains neutral with regard to jurisdictional claims in published maps and institutional affiliations. 